\title{
El Qhapaq Ñan en el valle de Calingasta (San Juan)
}

Alejandro García*

Recibido:

28 de enero de 2019

Aceptado:

20 de mayo de 2019

\section{Resumen}

El Qhapaq Ñan atravesaba longitudinalmente los valles preandinos sanjuaninos de Iglesia y Calingasta y su existencia en esta zona, sostenida desde mediados del siglo XX, ha sido recientemente confirmada. Como parte de nuestros estudios en el centro y sur de San Juan, relevamos recientemente el sector oriental del valle de Calingasta con el objeto de comprobar la conservación de evidencias del Qhapaq Ñan y de determinar el recorrido que seguía este ramal de la vialidad incaica en su paso hacia el norte de Mendoza. La búsqueda abarcó desde la villa de Calingasta ( ca. $\left.31^{\circ} 20^{\prime} \mathrm{S}, 69^{\circ} 25^{\prime} \mathrm{O}\right)$ hasta aproximadamente $32^{\circ} 04^{\prime} \mathrm{S}$. Los resultados de la misma indican la ausencia de evidencias del camino en el sector norte del valle, la presencia clara del mismo desde el este de la localidad de Barreal (ca. $31^{\circ} 38^{\prime} \mathrm{S}, 6^{\circ} 28^{\prime} \mathrm{O}$ ) hasta $c a .31^{\circ} 55^{\prime} \mathrm{S}$, y la ausencia de estructuras incaicas de envergadura en el sector relevado.

\section{The Qhapaq Nan in the Calingasta valley (San Juan)}

\begin{abstract}
The Qhapaq Nan crossed the San Juan pre-Andean valleys of Iglesia and Calingasta longitudinally, and its presence in this area (claimed since the mid-twentieth century) has recently been confirmed archaeologically. As part of our studies in central and southern San Juan, we recently surveyed the eastern side of Calingasta valley to find evidence linked to the preservation of the Qhapaq Nan, and to determine the location of this branch of the Inca road on its way towards the north of Mendoza. The search spanned from Calingasta town ( $\left.c a .31^{\circ} 20^{\prime} \mathrm{S}, 69^{\circ} 25^{\prime} \mathrm{W}\right)$ to approximately $32^{\circ} 04^{\prime} \mathrm{S}$. The results obtained indicate the absence of evidences of the path in the north of the valley, clear visibility of the road from the east of Barreal locality ( $c a .31^{\circ} 38^{\prime} \mathrm{S}, 69^{\circ} 28^{\prime} \mathrm{W}$ ) to ca. $31^{\circ} 55^{\prime} \mathrm{S}$, and the absence of major Inca structures in the surveyed area.
\end{abstract}

\footnotetext{
* Centro de Investigaciones de la Geósfera y la Biósfera (CIGEOBIO), Facultad de Ciencias Exactas, Físicas y Naturales, Universidad Nacional de San Juan (UNSJ) - CONICET. Av. José Ignacio de la Roza Oeste 727 (CP J5402DCH), San Juan, Argentina. E-mail: alegarcia@unsj.edu.ar
}

Palabras clave

Qhapaq Ñan Camino del Inca San Juan Dominio incaico

Keywords Qhapaq Ñan Inka Road San Juan Inca domination 


\section{Introducción}

Una de las claves de la expansión incaica fue el sistema vial estatal, que permitía una comunicación relativamente fluida entre los distintos sectores del imperio (Hyslop, 1984). Dado que el control incaico abarcó hasta el centro-norte de Mendoza (García, 1999), no resulta llamativo que los restos de aquel sistema llegaran a ese sector, para lo cual debían atravesar la actual provincia de San Juan (Bárcena, 2009; García, 2011). Los tramos más australes del Qhapaq Ñan por el lado argentino se observan en el valle de Uspallata, por lo que resulta esperable su vinculación con los valles preandinos del oeste sanjuanino. Así lo han reconocido todos los investigadores con experiencia en el tema (Aparicio, 1940; Bárcena, 1979; Hyslop, 1984; Raffino, 1981; Rusconi, 1962; Strube Erdmann, 1963), con la excepción de Debenedetti (1917). Paradójicamente, este autor es el único que ha brindado información relativamente aproximada sobre la ubicación del camino en el valle de Calingasta, a pesar de creer que su asignación cultural era errónea. A esta información se suman algunos datos brindados posteriormente por Bárcena (1979) sobre el sitio Tambería del Leoncito, además de la graficación del camino desde este sitio hacia el sur.

A fin de contrastar empíricamente la información transmitida por Debenedetti y de precisar el trazado y características del Qhapaq Ñan en la zona, se realizaron el análisis de imágenes satelitales y el relevamiento directo del sector del valle de Calingasta ubicado entre aproximadamente $31^{\circ} 20^{\prime} 30^{\prime \prime}$ y y la frontera con Mendoza (32 54'56"S). Algunos datos preliminares de este estudio fueron incorporados a una reconstrucción general de la vialidad incaica sanjuanina (García, 2017). Como continuidad de ese trabajo, el objetivo de la presente nota es brindar un panorama detallado del estudio del área, atendiendo especialmente a la localización y características de la senda y a la descripción de las estructuras asociadas a este tramo del camino.

\section{Aspectos metodológicos}

Tomando en cuenta los datos brindados por Debenedetti (1917), se relevaron extensos sectores del espacio localizado al este del río de los Patos-Calingasta, desde la localidad de Calingasta hasta la frontera con Mendoza. Previamente, se analizaron las imágenes satelitales disponibles en los programas Google Earth y Here, a fin de identificar posibles sendas que pudieran corresponder al camino.

La prospección se realizó a pie, y se priorizaron los sectores cuyo acceso era libre y que no estaban perturbados por la instalación de viviendas o por emprendimientos agrícolas. Dado que al sur de la localidad de Barreal la zona se encuentra cruzada por antiguas sendas, picadas y trazados de caminos previos a la ruta actual (todos los cuales contribuyen a generar expectativas acerca de la identificación de la vialidad indígena y a elaborar un escenario complejo para su análisis), todas estas alternativas fueron (previa contrastación con las hojas topográficas e imágenes satelitales de Google Earth correspondientes) transitadas y evaluadas a partir de la presencia o ausencia de evidencias arqueológicas.

Los tramos del Qhapaq Ñan fueron determinados a partir de su asociación directa con cerámica incaica (Figura 1). Los puntos de hallazgo fueron registrados con GPS y volcados al programa Google Earth, en el que se localizaron los tramos aún visibles y se trazaron las vinculaciones entre aquéllos. Las direcciones de los tramos fueron tomadas a partir de su representación sobre las imágenes de dicho programa. 


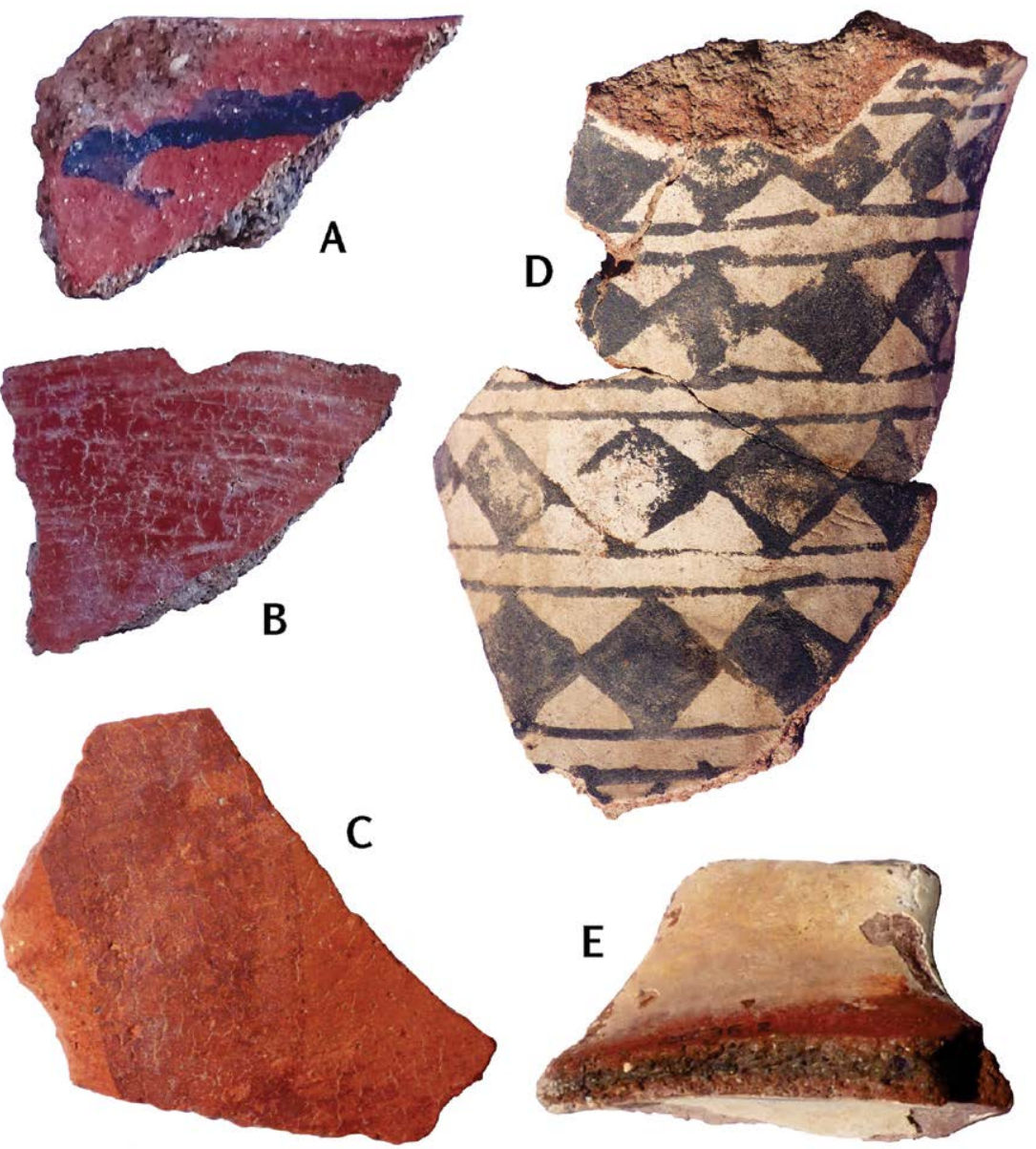

Figura 1. Cerámica incaica (A-D) y diaguita chilena inca asociada al Qhapaq Ñan en el valle de Calingasta. Los fragmentos de D) provienen del sitio Sorocayense.

\section{Características del Qhapaq Ñan en el valle de Calingasta}

\section{El Camino del Inca entre Barreal y Calingasta}

Según señala Debenedetti (1917), el camino incaico transitaba la margen derecha del río Castaño y sólo era visible en un sector ubicado al norte de Villa Corral. Al llegar a la confluencia con el río Calingasta, el camino pasaba a la margen derecha de éste. Si bien la senda no pasaba por la localidad de Calingasta, seguramente en esa zona se desprendía hacia el Oeste un ramal transversal que seguía el curso del río Calingasta, dada la presencia del sitio incaico Barrealito unos $11 \mathrm{~km}$ al Este-Sudeste.

Según Debenedetti, el camino seguía a muy corta distancia del río y unía las localidades de Hilario, Alto de Román y Sorocayense. En todo este sector, el espacio intermedio entre la llanura de inundación del río y las primeras estribaciones montañosas es muy estrecho y se encuentra totalmente afectado por actividades antrópicas (cultivos, asentamientos, la ruta) y naturales (fundamentalmente por los conos aluviales y las crecidas del río). La misma situación se observa a lo largo de varios kilómetros hacia el sur. Por lo tanto no es de extrañar que no se observen evidencias del camino incaico, ya que seguramente transitaba por la llanura de inundación o por la franja aledaña y estos sectores son frecuentemente alterados por las grandes crecidas del río de los Patos. 
Por eso no resulta llamativo que en el marco de estos estudios los primeros hallazgos vinculables con la dominación incaica se hayan encontrado recién en la localidad de Sorocayense ( $c a .31^{\circ} 33^{\prime} \mathrm{S}$ y $69^{\circ} 26^{\prime} \mathrm{O}$ ). Se trata de algunos fragmentos de cerámica incaica que aparecieron junto con otros de alfarería local, en un gran barreal que ha sido intensamente intervenido (Figura 1E).

Aproximadamente $5 \mathrm{~km}$ al norte de Barreal, existía una construcción rectangular de 27 por 19,50 m, cuyas paredes de piedra (de hasta $1 \mathrm{~m}$ de ancho) no superaban los 0,60 $\mathrm{m}$ de altura. Este sitio era conocido como Tambería de Barreal (Debenedetti, 1917) y, muy probablemente, la estructura registrada por Debenedetti haya sido parte de un conjunto mayor. La estructura rectangular no presentaba aberturas y tenía tres muros internos, dos transversales y uno longitudinal central, que conformaban seis cuadrángulos. Esta construcción guarda cierta similitud con las estructuras que de Hoyos y Williams (2017) consideran como una variante de los típicos recintos perimetrales compuestos. Las autoras mencionan cuatro hipótesis relacionadas con la función de estos sitios: depósitos, corrales, superficies destinadas a la agricultura y marcadores territoriales. Al respecto, las excavaciones de Debenedetti sólo brindaron una capa de guano a 15 $\mathrm{cm}$ de la superficie, lo que lo llevó a proponer que se trataba de corrales para encerrar ganado, probablemente llamas. Si bien la ausencia de aberturas internas o externas puede considerarse un obstáculo para este tipo de utilización, la altura de las paredes no impide la introducción de animales por encima de los muros, pero también se debe contemplar la posibilidad de que se haya tratado de espacios abonados, destinados a la realización de prácticas agrícolas.

Fuera del recinto se halló un fragmento de cerámica incaica y, si bien el autor no pudo distinguir el camino incaico en ese sector, admitió que "siguiendo su trazado, en lo que es posible observarlo, en la zona que está al sur de la tambería se ve claramente que marchaba en dirección tal que casi debía tocarla" (Debenedetti, 1917, p. 25). Asimismo, en la zona se descubrieron otros elementos probablemente incaicos, por ejemplo, puntas de proyectil líticas pequeñas triangulares con base cóncava o escotada y una punta de proyectil de hueso. En la actualidad no se observan restos de la construcción descripta por Debenedetti, la que recientemente ha sido confundida con un cementerio histórico de dimensiones bastante más reducidas (Escolar, 2003).

Los siguientes hallazgos recién se realizaron en un lugar ubicado al este de la localidad de Barreal. Desde este punto, puede seguirse de manera intermitente una senda que atraviesa un amplio cono aluvial y cuyo trazado ha podido ser constatado o reconstruido hasta aproximadamente $32^{\circ} 04^{\prime} 19^{\prime \prime}$ S, en el sector de la frontera con Mendoza. La recurrente aparición de cerámica incaica sobre esta senda o a sus costados indica claramente que se trata del camino longitudinal principal que conectaba el sur de San Juan con el valle de Uspallata.

\section{El trazado del Qhapaq Nan al este y sur de Barreal}

El segmento del Qhapaq Ñan registrado desde la localidad de Barreal hacia el sur tiene una extensión de 47.814 metros. En general, se trata de una senda simple, realizada mediante el despeje del terreno, sin demarcaciones especiales. Teniendo en cuenta los principales cambios de rumbo del camino se han determinado ocho tramos (Figura 2, Tabla 1).

El primer tramo observado (el más septentrional) comienza a $31^{\circ} 39^{\prime} 47^{\prime \prime} \mathrm{S}$ y atraviesa de manera sesgada un amplio cono de deyección que se abre desde una de las quebradas de la vertiente occidental precordillerana. Se trata de una senda despejada de ca. 1-1,5 $\mathrm{m}$ de ancho, sin demarcaciones laterales. En un sector del tramo se distingue una doble senda. A aproximadamente 1.200 metros del inicio del tramo, se observa al costado 


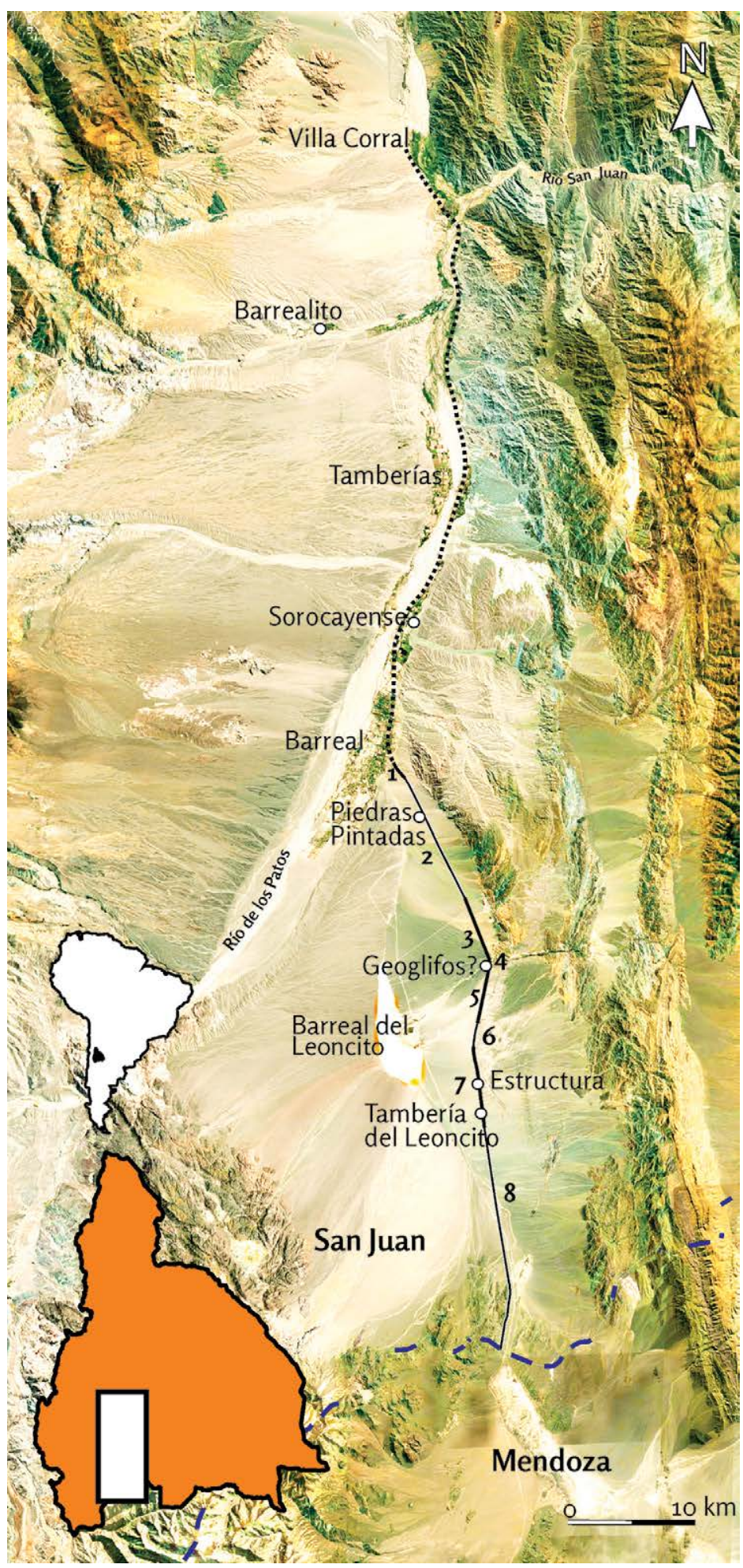

Figura 2. Ubicación del sector relevado (se numeran los tramos determinados) y de los principales sitios mencionados en el texto. La línea de puntos indica la probable localización del camino al norte de la localidad de Barreal.

del camino una forma sub-circular de rocas de 7,65 por 7,50 metros, con el borde marcado por rocas y el interior despedrado (Figura $3 \mathrm{~A}$ ). No se registraron materiales arqueológicos en el sector. 


\begin{tabular}{|c|c|c|c|c|c|}
\hline \multirow{2}{*}{ Tramo } & \multirow{2}{*}{$\begin{array}{l}\text { Extensión } \\
\text { (m) }\end{array}$} & \multicolumn{2}{|c|}{ Latitud } & \multirow{2}{*}{$\begin{array}{l}\text { Altura media } \\
\text { s.n.m. }\end{array}$} & \multirow{2}{*}{ Dirección } \\
\hline & & Extremo $\mathrm{N}$ & Extremo $S$ & & \\
\hline 1 & 1.580 & $31^{\circ} 39^{\prime} 47^{\prime \prime} \mathrm{S}$ & $31^{\circ} 40^{\prime} 26^{\prime \prime} \mathrm{S}$ & 1725 & $43^{\circ}$ Noroeste \\
\hline 2 & 10.220 & $31^{\circ} 40^{\prime} 26^{\prime \prime} \mathrm{S}$ & $31^{\circ} 45^{\prime} 20^{\prime \prime} \mathrm{S}$ & 1885 & $30^{\circ}$ Noroeste \\
\hline 3 & 5.320 & $31^{\circ} 45^{\prime} 20^{\prime \prime} \mathrm{S}$ & $31^{\circ} 47^{\prime} 59^{\prime \prime} \mathrm{S}$ & 2060 & $25^{\circ}$ Noroeste \\
\hline 4 & 374 & $31^{\circ} 47^{\prime} 59$ " S & $31^{\circ} 48^{\prime} \circ 8^{\prime \prime} \mathrm{S}$ & 2095 & $\begin{array}{l}47^{\circ} \text { Noroeste } \\
30^{\circ} \text { Noreste }\end{array}$ \\
\hline 5 & 4.760 & $31^{\circ} 48^{\prime} \circ 8^{\prime \prime} \mathrm{S}$ & $31^{\circ} 50^{\prime} 40^{\prime \prime} \mathrm{S}$ & 2040 & $7^{\circ}$ Noreste \\
\hline 6 & 2.160 & $31^{\circ} 50^{\prime} 40^{\prime \prime} \mathrm{S}$ & $31^{\circ} 51^{\prime} 50^{\prime \prime} \mathrm{S}$ & 1980 & $1^{\circ}$ Noreste \\
\hline 7 & 5.820 & $31^{\circ} 51^{\prime} 50^{\prime \prime} \mathrm{S}$ & $31^{\circ} 54^{\prime} 55^{\prime \prime} \mathrm{S}$ & 1995 & $12^{\circ}$ Noroeste \\
\hline 8 & 17.580 & $31^{\circ} 54^{\prime} 55^{\prime \prime} \mathrm{S}$ & $32^{\circ} 04^{\prime} 19^{\prime \prime} \mathrm{S}$ & 2103 & $\begin{array}{l}11^{\circ} \text { Noroeste } \\
6^{\circ} \text { Noreste }\end{array}$ \\
\hline
\end{tabular}

Tabla 1. Ubicación y dimensiones de los tramos del Qhapaq Ñan relevados.
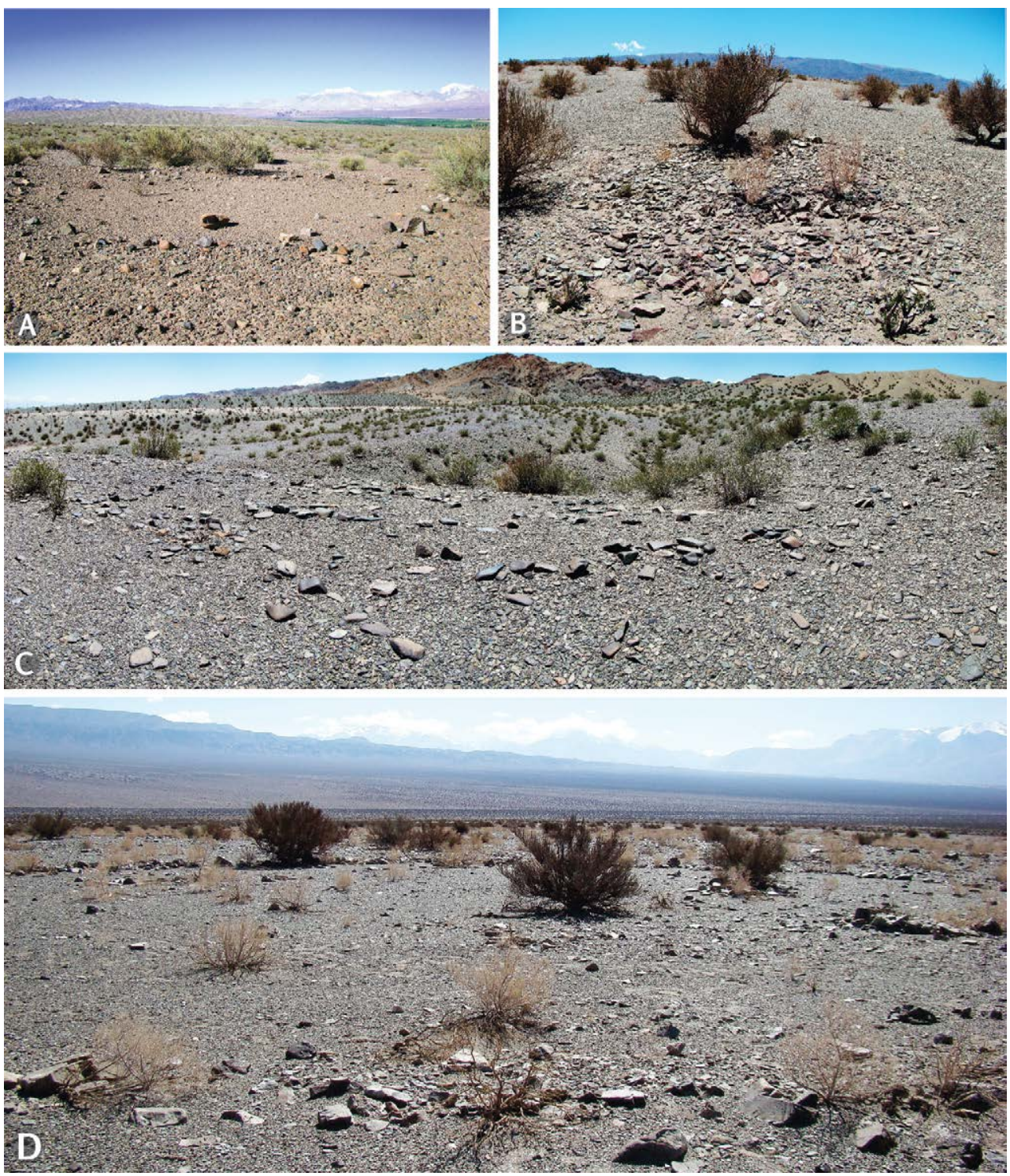

Figura 3. Estructuras asociadas al Qhapaq Ñan en el valle de Calingasta. A) Círculo despedrado; B) concentración de rocas y fragmentos de cerámica; $C$ ) posible geoglifo en el I sector de la Quebrada del Leoncito; D) vista parcial del sitio Tambería del Leoncito. 


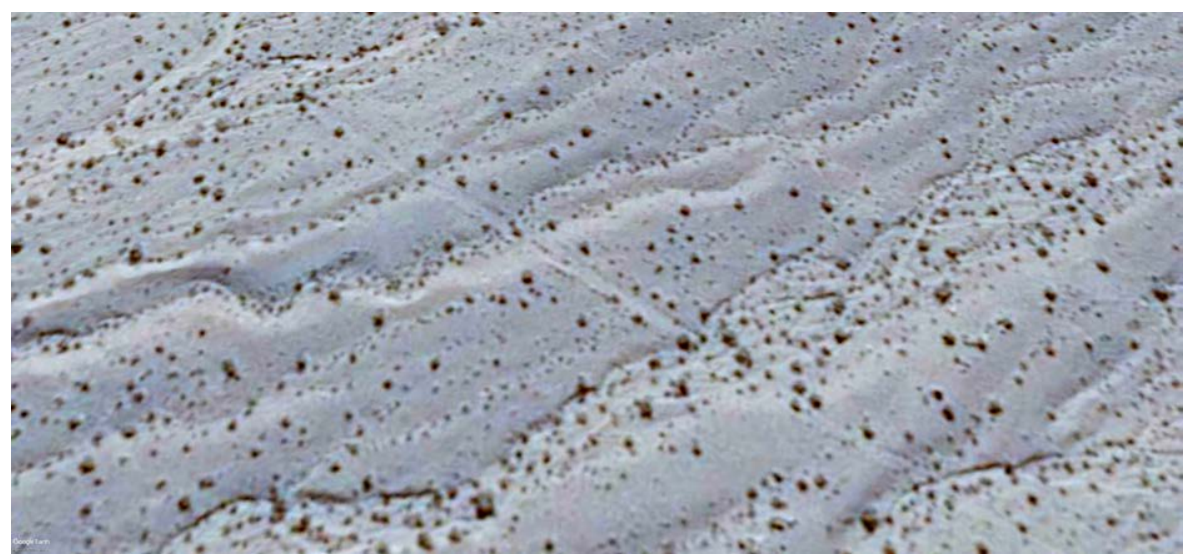

Figura 4. Vista aérea del camino en el sector no alterado del tramo 2 cercano al sitio Piedras Pintadas.

Luego de recorrer un poco más de $1,5 \mathrm{~km}$, el camino modifica su rumbo a $30^{\circ}$ Noroeste y continúa atravesando la serie de abanicos aluviales que caracterizan el paisaje a lo largo de todo el trayecto relevado. En este recorrido, la senda atraviesa algunos estrechos sectores levemente más elevados (Figura 4). En uno de ellos se encuentra el sitio arqueológico Piedras Pintadas, caracterizado por sus numerosas representaciones rupestres, y mencionado por Kuhn (1914) y Debenedetti (1917). Cabe consignar que en gran parte del tramo 2, el camino incaico coincide con la antigua traza del telégrafo, según se desprende del hallazgo de aisladores de loza, restos de postes y algunos de los agujeros correspondientes. Por otra parte, en estos sectores la senda presenta un ancho variable entre 4 y $8 \mathrm{~m}$, lo que hace suponer la superposición de un camino más reciente, posiblemente el vinculado con el servicio de mantenimiento de la línea de telégrafo.

El tercer tramo cambia levemente de dirección y continúa dirigiéndose hacia el Sudeste, hasta llegar al borde de la barranca profunda de la llanura de inundación de un cauce (Quebrada del Arroyo El Leoncito) que baja desde la precordillera en dirección Sudoeste.

Allí, el camino tuerce abruptamente (tramo 4) hacia el Sudeste y luego hacia el Sudoeste (bajada y subida de las laderas de la quebrada, respectivamente), para sortear el obstáculo mencionado. En medio de este tramo, sobre la margen izquierda del arroyo y tras subir la barranca meridional, se observa una serie de estructuras muy modificadas en la cima de una loma baja (Figura 3C). Se trata de alineaciones discontinuas de rocas de tamaño mediano, sin funcionalidad práctica evidente ni otro registro arqueológico asociado, que podrían considerarse como geoglifos, y tres círculos despedrados de entre 1,5 y 1,9 m de diámetro. Teniendo en cuenta la geomorfología local y que en la hoja topográfica correspondiente aparece en ese sector el topónimo "Lomas del inca", es posible que éste sea el lugar que dio origen a ese nombre.

Una vez que alcanza nuevamente la parte superior de la terraza del cauce, el camino vuelve a cambiar de rumbo y se dirige hacia el Sud Sudoeste (tramo 5), acercándose a las primeras estribaciones de la vertiente occidental precordillerana. A lo largo de unos $750 \mathrm{~m}$, el camino presenta un ancho de entre 3,5 y $4 \mathrm{~m}$ y una visibilidad regular, pero luego su detección se obstaculiza enormemente debido a las bajadas aluviales que lo cortan transversalmente. La visibilidad se pierde totalmente en el tramo 6, que ha debido ser tentativamente reconstruido a partir de las imágenes satelitales debido a que el camino se encuentra allí completamente tapado por sedimento. 
Desde la parte final de este tramo, el camino bordea a muy corta distancia las lomas precordilleranas, de las que se distancia recién en la última parte del tramo 7 . En éste la dirección ha cambiado significativamente y el camino se dirige hacia el Sud Sudeste (Figura 2). Aproximadamente a la mitad del tramo, la senda pasa junto a una estructura formada por una acumulación de clastos y rocas de colores diversos y de tamaño pequeño y mediano (Figura 3B). Tiene forma de óvalo, de 0,80 x 0,60 m. En el interior se encontraron varios fragmentos de cerámica incaica. A unos $4,40 \mathrm{~m}$ hacia el oeste, se observan los restos de un segmento de rocas de $0,60 \mathrm{~m}$ de ancho. El lugar presenta un marcado desnivel que permite distinguir tres escalones o niveles en el área de la estructura. No se advierte en las inmediaciones la existencia de recursos que pudieran brindar una razón práctica para la localización de esta estructura (agua, rocas, sombra, etc.).

A unos $300 \mathrm{~m}$ al sur, comienzan a distinguirse tres sendas paralelas que corren a corta distancia, sin que sea posible establecer si son coetáneas o tienen distinto origen. Unos $380 \mathrm{~m}$ al sur se agrega una cuarta senda; las cuatro se mantienen de manera discontinua en los próximos $1.500 \mathrm{~m}$, hasta el final del trayecto recorrido. En el sector final del tramo 7, las cuatro sendas tienen un ancho de 0,50 $\mathrm{m}$ y están separadas (de oeste a este) por distancias de $2 \mathrm{~m}, 1.7 \mathrm{~m}$ y 1,7 m (Figura 5A). En esta parte final, el camino atraviesa el sitio Tambería del Leoncito (Bárcena, 1979), que presenta una línea simple e irregular de rocas dispuestas en forma de arco, con dos pircados sub-circulares y uno oval en su interior (Figura 3D). Esta estructura tiene $33 \mathrm{~m}$ de largo por $15 \mathrm{~m}$ de ancho. Al pasar por este sitio el camino incaico tiene sólo $2 \mathrm{~m}$ de ancho. Al costado este del camino se observan algunos alineamientos de rocas que probablemente sean restos de otras estructuras. Bárcena (1979) menciona haber excavado algunas estructuras anexas, de las que extrajo escasos fragmentos de cerámica. A pesar del nombre impuesto al sitio, este autor descarta la funcionalidad de albergue y se inclina a considerar que el lugar fue un sitio ceremonial secundario.

Hacia 31 $54^{\prime} 55^{\prime \prime}$ S, el camino deja de ser reconocible en el paisaje, que en esta zona está totalmente modificado por las crecidas aluviales que bajan ocasionalmente de la precordillera. Sin embargo, en las imágenes satelitales se detectan débiles rastros que permiten continuar tentativamente el trayecto hasta el límite interprovincial. A lo largo de 7,8 km el camino cruza numerosos interfluvios y cauces ocasionales sobre el costado oriental de la Ruta Provincial $N^{\circ} 149$, con una dirección general Nor noroeste-Sud sudeste. Luego de traspasar la ruta, mantiene esa dirección a lo largo de aproximadamente $4,25 \mathrm{~km}$, hasta llegar a unas lomadas baja en ca. $32^{\circ} 01^{\prime} 29^{\prime \prime} \mathrm{S}$ y $69^{\circ} 21^{\prime} 19^{\prime \prime}$ O. Después de atravesar un sector de estas lomadas, la senda cambia su dirección a Nor nordeste-Sud sudoeste y corre entre las lomadas y la ruta hasta alcanzar el límite interprovincial. En varios sectores de esta última parte del tramo se observan en las imágenes satelitales varias sendas paralelas (entre dos y cinco), en trayectos cortos (Figura 5B). El relevamiento de algunos sectores de este tramo permitió constatar una baja visibilidad del camino y de materiales arqueológicos asociados, fundamentalmente en los cauces esporádicos que atraviesan la zona transversal y oblicuamente. Este último tramo coincide aproximadamente con el propuesto por Bárcena (1979), aunque se registran algunas diferencias de dirección y localización, que parcialmente podrían relacionarse con los distintos sistemas de graficación utilizados.

\section{Consideraciones finales}

La verificación parcial de la información ofrecida por Debenedetti (1917) sobre el trazado de lo que los lugareños conocían como Camino del Inca en el valle de Calingasta, indica que los datos que recabó eran correctos y que el principal camino longitudinal de la vialidad incaica atravesaba la zona siguiendo básicamente la trayectoria delineada en su mapa. El ensanchamiento de la llanura de inundación del río de los Patos y el avance de la utilización agrícola de su margen derecha han provocado un cambio 


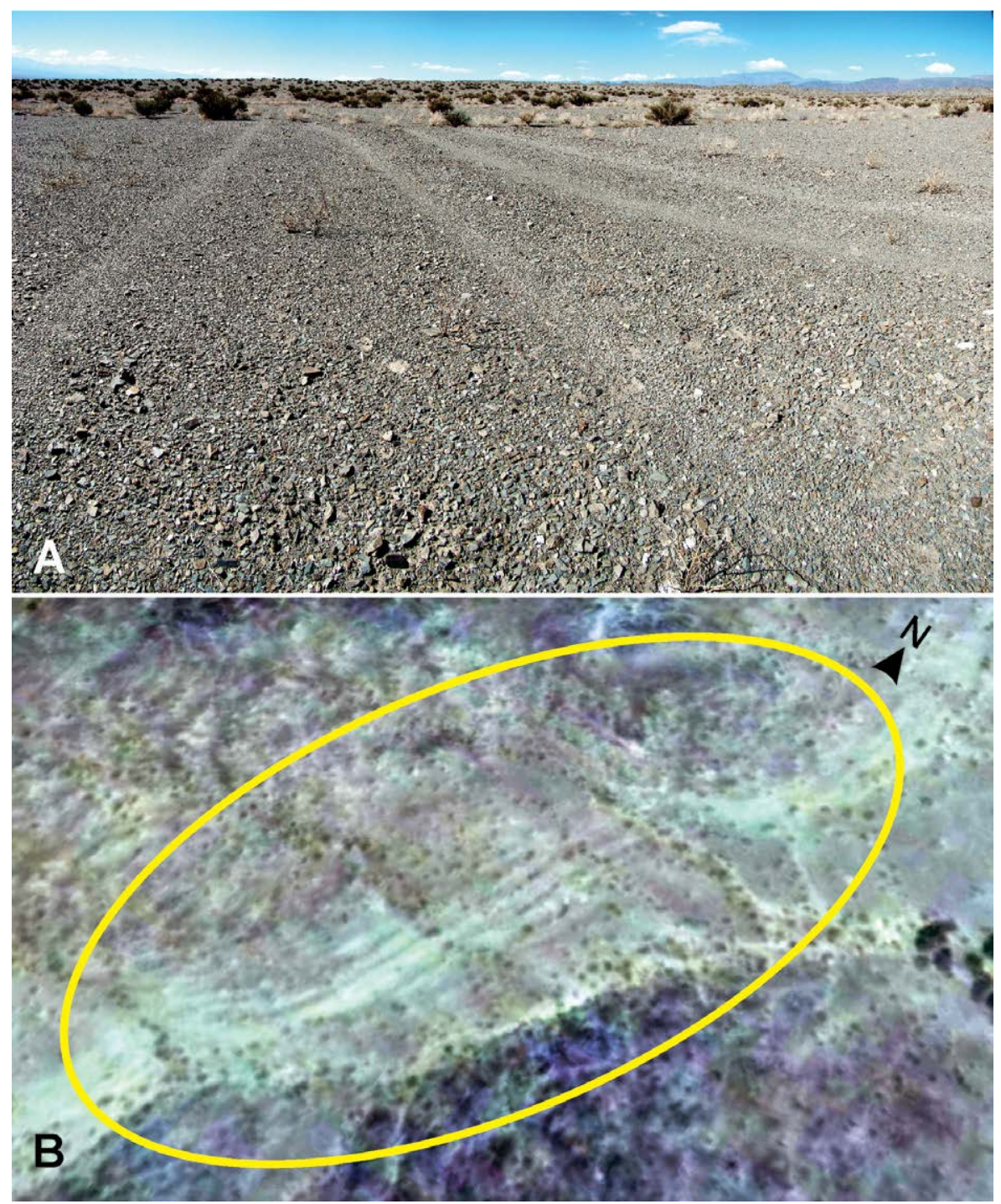

Figura 5. Vistas de tramos con múltiples sendas. A) Sector con cuatro sendas paralelas, cerca de la Tambería del Leoncito; B) Sendas paralelas cerca del límite con Mendoza.

importante en el paisaje del valle en los últimos 100 años. Debido a ello, los restos de gran parte del Qhapaq Ñan, que según Debenedetti costeaba la margen derecha a muy corta distancia del río, parecen haberse borrado.

Dado que la falta de datos concretos sobre la ubicación de la vialidad incaica en el oeste sanjuanino ha dado lugar a planteos alternativos sobre su localización, la constatación de que desde la Tambería del Leoncito (donde el Qhapaq Nan fuera observado por Bárcena) hacia el norte el camino se desarrollaba sobre la ladera oriental del valle de Calingasta es importante para clarificar el tema. Específicamente, aquella verificación permite desestimar la propuesta que ubicaba al Qhapaq Nan a lo largo del sector precordillerano vecino (Michieli, 2001).

Un aspecto importante es la ausencia general de demarcación o amojonamiento del camino y la falta de asociación con elementos naturales que puedan ser considerados como huacas (Orgaz, Kristcautzky y Caletti, 2007). Por el contrario, resulta significativa la presencia de al menos dos sitios con una posible función simbólica y ritual (los dos descriptos en el tramo 7), uno cruzado por el camino y el otro a la vera del mismo. 
En el caso del sitio formado por la concentración de rocas y clastos, la presencia de tiestos correspondientes a diversas piezas cerámicas en su interior (entre ellas, una negra pulida, extraña en contextos incaicos de la región), y de sedimento y rocas con signos de termoalteración (clara evidencia de eventos de combustión en el lugar García y Zárate, 1999-) en una superficie relativamente reducida y funcionalmente inadecuada para actividades prácticas, sugiere la realización de ofrendas y/o la rotura ritual de vasijas. Igualmente llamativa resulta la presencia de las superficies despedradas y los probables geoglifos del Arroyo El Leoncito, cuya funcionalidad podría vincularse fundamentalmente con aspectos ideológicos.

Como ya se ha señalado en relación con la continuación del camino por el valle de Iglesia (García, 2011), uno de los motivos por los que Debenedetti descreía del carácter incaico de esta senda era la ausencia de construcciones monumentales de origen claramente estatal. De hecho, desde Tocota hasta Tambillos (en el valle de Uspallata) hay cerca de $190 \mathrm{~km}$ en línea recta sin construcciones incaicas de envergadura. Sin embargo, es probable que éstas hayan existido en las localidades de Calingasta, Tamberías y/o Barreal. Aun así, entre Barreal y Tambillos el camino recorre más de $80 \mathrm{~km}$ en los que no se observa infraestructura adecuada para el depósito de alimentos, para el aprovisionamiento o pernocte de mucha gente ni para el encierro de animales. Lo anterior podría llevar a desestimar la utilización masiva del camino, por ejemplo para el traslado de fuerzas militares. Sin embargo, esta idea contrasta con la presencia de largos tramos con sendas múltiples, que podrían explicarse por la necesidad de aligerar el paso de grupos de gran tamaño. Además, existen en otros sectores del Tawantinsuyu varios casos en los que el camino está constituido por una senda despejada y no se observan estructuras monumentales asociadas a lo largo de extensos recorridos. Tales son los casos del Despoblado de Atacama, en el norte de Chile (más de $170 \mathrm{~km}$ ) y de algunos tramos menores que unen los valles de Asia, Cañete y Chincha, en el sur de Perú (González Godoy, 2007, 2017; Hyslop, 1984).

Recientemente, Marsh, Kidd, Ogburn y Durán (2017) propusieron que la anexión de Mendoza al Tawantinsuyu se habría realizado mucho antes de lo indicado por los datos etnohistóricos, quizás entre 1380 y 1430 d.C. Una de las consecuencias de esta importante extensión del período incaico local debió ser el aumento de la intensidad de la comunicación con los territorios septentrionales a través del Qhapaq Ñan. Sin embargo, la ausencia de estructuras y de elementos tendientes a jerarquizar esta parte del sistema vial contrasta marcadamente con la idea de un uso prolongado del camino, vinculable con una anexión temprana, y se ajusta mejor a una cronología más tardía para la incorporación incaica de Cuyo.

En definitiva, tanto las características de la vialidad como las de las construcciones asociadas deben estar relacionadas con el avance específico del proceso de dominación de la región, por lo que su comprensión posiblemente dependa en gran medida de futuros estudios sobre el tránsito del Qhapaq Ñan, de un mejor conocimiento de la funcionalidad de los sitios y de una discusión y ajuste continuos de los modelos generales que intentan explicar la anexión y el dominio incaico de Cuyo.

\section{Agradecimientos}

Este trabajo se enmarca en proyectos de investigación financiados por CICITCA-UNSJ y CONICET (PUE 2292016010 Recursos de la provincia de San Juan: conflictos de uso, peligros y prioridades de conservación, su estudio a dos escalas). Agradezco a Nadia Rodriguez, Ana Eguaburo, Anabel Rodriguez, Rubén Giaconi, Diego Heredia, Susana Carrizo, Andrés Kummel, Oscar Riveros y Oscar Damiani por su valiosa colaboración en las tareas de campo. Extiendo mi agradecimiento a los evaluadores del manuscrito, por sus amables y valiosos comentarios y sugerencias. 


\section{Referencias citadas}

"Aparicio, F. de. (1940). Ranchillos; tambo del inca en el camino a Chile. Anales del Instituto de Etnografía Americana, I, 245-253.

" Bárcena, J. R. (1979). Informe sobre recientes investigaciones arqueológicas en el N.O. de la Provincia de Mendoza (Valle de Uspallata y zonas vecinas) (con especial referencia al periodo incaico). Actas del VII Congreso de Arqueología de Chile, (Tomo II) (pp. 661692). Santiago de Chile: Kultrún.

» Bárcena, J. R. (2009). Aportes 2000-2001 al conocimiento de la dominación incaica del Centro Oeste Argentino. En F. Oliva, N. de Grandis y J. Rodriguez (Comps.), Arqueología Argentina en los inicios de un nuevo siglo, (Tomo I) (pp.131-142). Rosario: Laborde Editor.

»Debenedetti, S. (1917). Investigaciones arqueológicas en los valles preandinos de la provincia de San Juan. Buenos Aires: Facultad de Filosofía y Letras, Universidad de Buenos Aires.

» de Hoyos, M. y Williams, V. (2017). Abran kancha... Una variante de recinto perimetral compuesto en el noroeste argentino. Estudios Atacameños, 55, 109-134.

》Escolar, D. (2003). Arqueólogos y brujos: la disputa por la imaginación histórica en la etnogénesis huarpe. Relaciones de la Sociedad Argentina de Antropología, XXVIII, 23-43.

" García, A. (1999). Alcances del dominio incaico en el extremo suroriental del Tawantinsuyu. Chungara. Revista de Antropología Chilena, 29(2), 195-208.

" García, A. (2011). El Camino del Inca entre Tocota y Villa Nueva (San Juan). Revista del Museo de Antropología, 4, 89-98.

» García, A. (2017). La vialidad incaica en la provincia de San Juan (Argentina). Boletín del Museo Chileno de Arte Precolombino, 22(1), 137-150.

» García, A., y Zárate, M. (1999). Perdurabilidad y cambios de fogones experimentales en la precordillera mendocina. Arqueología, 9, 105-121.

»González Godoy C. (2007). Qhapaq Ñan en el extremo meridional del despoblado de Atacama, Chile. Actas del XVII Congreso Nacional de Arqueología Argentina, (Tomo II) (pp. 511-518). Jujuy: Universidad Nacional de Jujuy.

" González Godoy, C. (2017). Arqueología vial del Qhapaq Ñan en Sudamérica: análisis teórico, conceptos y definiciones. Boletín del Museo Chileno de Arte Precolombino, 22(1), 13-32.

》 Hyslop, J. (1984). The Inka Road System. Nueva York: Academic Press.

"Kuhn, F. (1914). Estudios sobre petroglifos de la región diaguita. Buenos Aires: Facultad de Filosofía y Letras, Universidad de Buenos Aires, Conni Hermanos.

» Marsh, E., Kidd, R., Ogburn, D. y Durán, V. (2017). Dating the expansion of the inca empire: bayesian models from Ecuador and Argentina. Radiocarbon, 59(1), 117-140.

»Michieli, C. T. (2001). Tambos incaicos del centro de San Juan: su articulación regional. Scripta Nova. Revista Electrónica de Geografía y Ciencias Sociales, 70, 1-22.

»Orgaz, M., Kristcautzky, N.yCaletti, S. (2007). Infraestructura vial inka en el Departamento de Andalgalá - Catamarca - Argentina. Actas del XVI Congreso de Arqueología Argentina (Tomo II) (pp. 519-524). Jujuy: Universidad Nacional de Jujuy.

» Raffino, R. (1981). Los incas del Collasuyu. La Plata: Ramos. 
» Rusconi, C. (1962). La tambería prehispánica de Tocota (San Juan). Revista del Museo de Historia Natural de Mendoza, XIV(1-4), 25-30.

» Strube Erdmann, L. (1963). Vialidad Imperial de los Incas. Desde Colombia hacia Chile Central y Sur de Mendoza (Argentina) con inclusión de sus proyecciones orientales (Serie Histórica № 33). Córdoba: Universidad Nacional de Córdoba, Facultad de Filosofía y Humanidades, Instituto de Estudios Americanistas. 